\title{
Mulemba
}

Revista Angolana de Ciências Sociais

\section{O mito da portugalidade no ensino colonial: a história e a razão metonímica}

The Myth of Portugal throughout the colonial education: the story and the metonymic reason

\section{Catarina Antunes Gomes}

\section{(QpenEdition Journals}

\section{Edição electrónica}

URL: http://journals.openedition.org/mulemba/263

DOI: $10.4000 /$ mulemba.263

ISSN: 2520-0305

\section{Editora}

Edições Pedago

\section{Edição impressa}

Data de publição: 1 novembro 2014

Paginação: 127-142

ISSN: 2182-6471

Refêrencia eletrónica

Catarina Antunes Gomes, «O mito da portugalidade no ensino colonial: a história e a razão metonímica», Mulemba [Online], 4 (8) | 2014, posto online no dia 28 novembro 2016, consultado o 26 janeiro 2021. URL: http://journals.openedition.org/mulemba/263 ; DOI: https://doi.org/10.4000/ mulemba.263

Este documento foi criado de forma automática no dia 26 janeiro 2021.

Tous droits réservés 


\section{0 mito da portugalidade no ensino colonial: a história e a razão metonímica}

The Myth of Portugal throughout the colonial education: the story and the metonymic reason

\section{Catarina Antunes Gomes}

\section{NOTA DO EDITOR}

Artigo solicitado a Autora

Recepção do manuscrito: 30/10/2014

Conclusão da revisão: 30/11/2014

Aceite para publicação: 10/12/2014

\section{Enquadramento}

1 Enquanto sector da política colonial portuguesa, a instrução e a educação colonial serão abordadas como elemento estruturante da dominação colonial e como campo de exercício da razão metonímica (cf. SANTOS 2002; 2006). Segundo Boaventura de Sousa Santos, a razão metonímica constitui uma das dimensões do que denomina de razão indolente, a qual designa o gigantismo da mesmidade epistémica, de carácter marcadamente expansivo, colonial e capitalista, nos domínios social, político, filosófico e científico da modernidade ocidental. A razão metonímica é guiada pela ideia obsessiva de totalidade codificada como ordem. Afirma-se, desse modo, exaustiva, tudo englobante, completa. Neste sentido, «a razão metonímica diminuiu ou subtraiu o mundo tanto quanto o expandiu ou adicionou com as suas próprias regras» (SANTOS 2002: 245). Significa isto que o que define a razão metonímica é a cooperação entre dois mecanismos: o primado da auto-referencialidade, por um lado, e, por outro, a sua 
expansão por via da domesticação/conversão/normalização do diverso, transformado em matéria-prima da própria razão metonímica. As linhas abissais que esta razão vai desenhando são ainda blindadas por uma segunda consequência: é que, no modelo da razão metonímica, as partes não possuem vida própria, além e/ou fora do todo - que é uma parte - que lhes atribui lugar e sentido. Elas produzem a impossibilidade de as partes serem outra coisa que não partes da razão metonímica. Trata-se de um mecanismo central da produção da subalternidade.

2 Procurar-se-á, pois, problematizar a temática da instrução e educação colonial em Angola, focando especialmente a década de 1960. Trata-se, fundamentalmente, de uma tarefa de contextualização histórica que pretende dar visibilidade às formas de violência epistémica exercidas pela autoridade colonial e de instrumentalização das políticas de instrução e de educação em prol da defesa do domínio colonial.

Trata-se também de um exercício que apresenta algum grau de dificuldade, pois, como demonstra João Carlos Pinto, «os actuais conhecimentos históricos sobre o tema são insatisfatórios, não só pela inexistência de trabalhos [...], mas também porque os que existem necessitam, regra geral, de uma avaliação crítica que tenha em conta os pressupostos que thes estão subjacentes». De facto, «a análise dos fenómenos educativos limita-se, praticamente até à década de 1970, a ser um mero repositório de leis e de intenções, ambas passíveis de comprovar o mérito da "acção colonizadora, evangelizadora e civilizadora dos portugueses nos trópicos"» (1996: 113-115). ${ }^{1}$

\section{Contextualização²}

Globalmente, durante o século XIX, não se encontra nenhum pensamento estruturante que dê corpo a uma política unificada de educação colonial. Destacar-se-ão, em seguida e de modo muito sumário, alguns dos momentos mais significativos da titubeante política colonial portuguesa no âmbito da instrução e da educação. Assim, há a salientar a implantação, em 1845, do ensino oficial em Angola, com a criação das escolas de ler, escrever e contar (as chamadas "escolas principais de instrução primária») em Luanda $\mathrm{e}$ Benguela, por decreto assinado por Joaquim José Falcão. ${ }^{3} \mathrm{~A}$ instrução pública primária passa a ser estruturada em nível elementar e nível complementar, sendo estes dirigidos às populações «evoluídas». Para além destas escolas, cogitava-se ainda sobre a instauração das Escolas Rudimentares, destinadas, desta feita, às populações indígenas.

5 Pese embora a divergência de opiniões no que diz respeito às modalidades e objectivos a adscrever à instrução e educação dos indígenas, observada até à primeira metade do século XX (PINTO 1996; NORÉ e ADÃO 2003), a centralidade da questão associada à formação de um reservatório de mão-de-obra nas colónias merecia consenso. Assim, no âmbito da reformulação da política colonial no início dos anos de 1920, Norton de Matos advogava um certo assimilacionismo cauteloso, gradual e tendencial, preconizando as instituições de instrução mais no sentido de oficinas do que escolas. ${ }^{4}$ Em 1927, é decretado, pelo Diploma legislativo n.o 518 de 16 de Abril, o plano geral de remodelação do ensino primário:

«Pretendendo satisfazer às necessidades mentais de dois grupos étnicos, naturalmente tão distanciados, como o europeu e o africano, esta reorganização procura estabelecer [...] dois ramos assimétricos [...] o ensino para os europeus e assimilados e o ensino para os indígenas». 
Esta reorganização do sistema escolar e de instrução ocasiona ainda, em 1930, pelo Diploma legislativo n. 238 de 17 de Maio, a institucionalização da separação dos objectivos de cada tipo de ensino: o ensino indígena tem por fim «elevar gradualmente da vida selvagem à vida civilizada dos povos cultos a população autóctone das províncias ultramarinas», e o ensino primário elementar para os «não-indígenas» visava a «dar à criança os instrumentos fundamentais de todo o saber $e$ as bases de uma cultura geral, preparando-a para a vida social». Na década seguinte, dois importantes acordos vão aprofundar esta orientação política: o Acordo Missionário (Maio de 1940) e o Estatuto do Missionário (1941). ${ }^{5}$ Maria da Conceição Neto refere a este propósito o seguinte:

«A Igreja Católica, reforçada com a Concordata de 1940 e o Acordo Missionário de 1941, pôs as instituições de formação de que dispunha (seminários, escolas de professores primários) ao serviço da "portugalização", de forma expressa: "O curso de professores da Escola Teófilo Duarte é essencialmente católico, nacionalista e prático. Queremos [...] um católico convicto, um português consciente e um mestre que resulte" [COSTA 1970: 266-267]» (1997: 336).

O início da luta armada contra o domínio colonial português foi acompanhado por um esforço acrescido de investimento em Angola nos mais diversos domínios, incluindo na esfera da educação. Este projecto conservava, no entanto, «a imagem ambígua dos efeitos que uma educação para as massas poderia desencadear, sendo visível que a [...] crença na escolarização como meio privilegiado de modernização [...] não exclui as frequentes alusões aos "efeitos perversos" da educação, efeitos capazes de gerar o crescente número de "desenraizados" adeptos de soluções pró-independência» (PINTO 1996: 109-110).

8 A 1 de Janeiro de 1964, foi criada a Secretaria Provincial de Educação em Angola, sendo a mesma entregue a José Pinheiro da Silva (1964-1971), mestiço nascido em Cabinda, e salazarista convicto no Portugal pluri-continental e multi-racial. ${ }^{6}$ A criação da Secretaria constituiu um importante marco no ensino colonial em Angola e a sua actuação estava claramente orientada para participar e contribuir para a consolidação de uma «Angola Portuguesa» que resistisse e eliminasse as forças opositoras e independentistas. A expansão da educação portuguesa pelos territórios da Província, enquanto forma de assegurar a presença portuguesa, controlar as comunidades e de converter a potencial «subversão» em adesão aos ideais da portugalidade, constituía-se como o meta-objectivo da administração colonial.

9 Meses depois, o Decreto-Lei n. 43.893 de 10 de Setembro de 1964 marca uma nova reforma do ensino primário elementar sob os desígnios de uma rápida cobertura escolar nas províncias. Justino Mendes de Almeida, Director Geral do Ensino do Ultramar, reitera o discurso ideológico do Estado Novo no que diz respeito à Nação pluri-continental e pluri-racial no campo da educação:

«uma só orientação domina o legislador: a preocupação de unidade educativa no espaço português. [...] Unidade educativa, um só ensino para todos os Portugueses, as mesmas escolas, os mesmos programas, enfim, ensino à nossa medida de Portugal» (Ultramar, 5/2, 4. ${ }^{\circ}$ trimestre de 1964, cit. in PINTO 1996: 107).

10 A educação era encarada, simultaneamente, como instrumento de luta contra a «insurreição terrorista» que se espalhava por Angola, ${ }^{7}$ e como um instrumento de promoção da adesão das comunidades à portugalidade, tornando-as imunes à «rebelião».

11 Será, pois, um ideal instrumental de portugalidade e os propósitos de afrontamento e neutralização das ideologias nacionalistas, que irão orientar a acção educativa colonial. 
Esse ideal de portugalidade servirá ao fortalecimento dos propósitos «integracionistas»e «assimilacionistas», na medida em que «todos quantos pensam, sentem e agem à luz dos valores morais, espirituais e religiosos da Casa Lusitana são portugueses. Em rigor, a integração é, entre nós, uma mentalidade. Define um estilo de vida» (SILVA 2010: 16). A educação constituía-se, assim, como um veículo privilegiado do processo que Isabel Castro Henriques denuncia como sendo de «branquização» - processo que designa não só o afluxo de colonos brancos, mas também "a "branquização" do quotidano dos africanos, retirando-lhes qualquer forma de autonomia: comer, vestir, falar, rezar, trabalhar, organizar a casa segundo os modelos europeus» (2003: 14). Este assimilacionismo participa, claramente, num leque vasto de estratégias que incluíam o epistemicídio dos saberes e conhecimentos das populações (cf. SANTOS, MENESES e NUNES 2004; SANTOS e MENESES 2011) - estratégias estas que almejam uma desarticulação e uma negação do colonizado como sujeito autónomo, legitimadas pelos propósitos da missão civilizadora portuguesa. Neste âmbito, uma das preocupações mais caricatas da administração provincial durante os anos de 1960 foi a de substituir o regime alimentar local e nativo, vigente em muitas escolas, pela gastronomia nacional metropolitana, por se considerar que aquele seria «contrário ao interesse nacional». A alimentação era assim vista como «elemento indispensável a uma séria política de plena integração» (SILVA 2010: 12).

\section{A Portugalidade no ensino colonial}

12 Analise-se agora o programa do ensino primário ultramarino, anexado à referida portaria ministerial de 19 de Fevereiro de 1964 - peça central da reforma educativa dos anos de 1960, focando-se, por razões de economia de texto, algumas das disciplinas ministradas.

Tomemos o exemplo da Geografia. O objectivo fulcral será o de:

«Ao ensinar a geografia de Portugal, o professor terá sempre presente a intenção de dar às crianças a consciência da unidade portuguesa, uma unidade intercontinental e interoceânica. $O$ estudo paralelo da história pátria ajudará a compreender melhor o sentido real e profundo desta unidade» (Programa do Ensino Primário Ultramarino 1964).

No que diz respeito à disciplina da «Língua Nacional», a aprendizagem do português não podia deixar de obedecer a este ideal. 0 ensino era, ainda, servido por uma multiplicidade de técnicas que passava pelo treino intensivo da oralidade quotidiana, pela correcção constante da pronúncia, por exercícios de ortografia e da caligrafia oficial, pelo aperfeiçoamento da expressão oral em língua portuguesa e por exercícios diários para a correcção de "vícios de construção gramatical»:

«Já na 1. classe (2.ำ ano) o professor deve exercer cuidadosa vigilância aos erros de prosódia mais frequentes, para os corrigir. Chama-se especial atenção para a supressão de consoantes e supressão dos rr e ss finais (fazê por fazer; mêmo por mesmo, etc.) troca do 1 pelo $\mathrm{r}$ ou pelo $\mathrm{u}$ (animar ou animau por animal); supressão do i dos ditongos ei e confusão entre o timbre do e tónico aberto e o e tónico fechado (dinhêro por dinheiro, sête por sete, fés por fez, etc.); erros de concordância (eu vi os macaco, o galinha morreu); erros de construção (ir na escola) (ir em casa) (o leão atacou-lhe, etc.); pronúncia errada do e mudo medial (minino por menino); errada pronúncia da soma dos dois aa, um terminal e outro inicial, ambos fechados num só a aberto e átono (iapanhar, em vez de iàpanhar), falta de abertura do a átono precedendo a sílaba tónica (translação em vez de translàção, etc.); má pronúncia dos vários timbres do a e do o, etc. É muito importante que não 
se permita aos alunos a radicação destes erros, para que não entrem no hábito da língua corrente» (Programa do Ensino Primário Ultramarino 1964). uma selecção textos que deveriam ser incluídos no livro de leitura. Estes textos
ilustravam os momentos canónicos da história oficial do Portugal europeu e do Portugal descobridor, tais como "Viriato: Vida dos Lusitanos e suas lutas com os Romanos invasores», «Egas Moniz: O educador do rei; serviços prestados ao rei e à Pátria; o seu acto de lealdade», «O Castelo de Guimarães: Símbolo da fundação de Portugal», «Santo António de Lisboa: Breves notas sobre a sua vida e o seu culto», «Rainha Santa Isabel: Traços mais salientes da sua acção», «Nuno Álvares Pereira: Sentido patriótico da sua actuação; sua vida de monge; o culto tradicional oficializado», «Infante D. Henrique: Os Descobrimentos. Sagres», «Vasco da Gama: Importância da primeira viagem à Índia por mar, para Portugal e para o Mundo», «Pedro Álvares Cabral: $O$ descobrimento do Brasil», «Afonso de Albuquerque: Acção na Índia; prestígio de Portugal no Oriente», «1.ㄹ de Dezembro de 1640: A Restauração. A nova dinastia portuguesa», «O terramoto de 1755: A reconstrução de Lisboa», «Portugal em África: As grandes viagens de exploração», «A unidade portuguesa no Mundo de hoje: D. Aleixo Corte Real; Aniceto do Rosário (muitas raças - uma só nação)».

o programa da disciplina incide sobre a Lusitânia, a resistência face às invasões romanas, o papel de Viriato, a romanização e cristianização da Península Ibérica, as invasões de Suevos, Visigodos e Mouros, o Condado Portucalense, a fundação do reino e a conferência de Zamora, a Reconquista, a organização do reino, as dinastias, políticas de desenvolvimento do reino, a expansão além-mar, a obra evangelizadora, a literatura, arte e ciência, a Restauração, as invasões francesas, o «reino unido de Portugal e Brasil», o liberalismo, «Portugal em África», a República, a I Guerra Mundial, o 28 de Maio e o Estado Novo Corporativo, a organização política e administrativa da Nação, e, naturalmente, os símbolos da Pátria.

De facto, a importância do ensino da história nas tentativas de conversão e domesticação dos sujeitos colonizados (MUDIMBE 1988), revelava-se fundamental:

«O ensino da história na escola primária destina-se a consolidar o natural sentimento de patriotismo, dando-lhe forma consciente e esclarecida. 0 amor da Pátria não pode ser considerado como uma consequência lógica do conhecimento do passado (podemos admirar entre todos o povo romano, e nem por isso teremos um patriotismo romano), mas sim como uma relação natural do indivíduo ao meio a que pertence, muito mais semelhante ao amor dos filhos pelos pais do que à admiração do aluno pelo mestre ou do leitor pelo escritor preferido, e sobretudo extremamente distante da fria conclusão de um raciocínio. Mas o estudo da história aprofunda o conhecimento do presente e, nos nossos antepassados, mostra-nos quem somos. Não se trata de dizer aos alunos que a história de Portugal é uma série ininterrupta de acções gloriosas; que tudo no passado português foi exemplar. Mas é perfeitamente lícito escolher, para objecto de um ensino eminentemente formativo (como é o ensino primário), alguns dos momentos mais belos e dignificantes da nossa história. Da abundância destes dá testemunho a dificuldade 
que tem de vencer quem se proponha organizar os programas da 3.. e $4 .{ }^{a}$ classes. $\mathrm{Na}$ escola primária, portanto, a história será a "mestra do futuro" e ajudará a definir as grandes linhas da presença portuguesa intercontinental e pluri-racial no mundo contemporâneo, e assim, sem nada perder do seu carácter de sentimento vivo, o patriotismo será uma consciência clara» (Programa do Ensino Primário Ultramarino 1964).

\section{A portugalização, o ensino da História e a razão metonímica}

É por demais evidente a conjugação harmoniosa pretendida entre o leque curricular do ensino colonial, onde os conteúdos programáticos determinados veiculam a noção de uma «portugalidade» que, embora seja pluri-continental e pluri-racial, redunda numa monocultura (branca e metropolitana) que se reclama de universalidade.

Muito especialmente no que diz respeito ao conhecimento produzido pelo colonialismo, Donatien Dibwe dia Mwembu expressa o seguinte: «Colonial history is a history of whites in Africa insofar as it focuses on the deeds and activities of the colonizers and leaves in the shadows the contribution of those being colonized to the birth and development of the colonial enterprise» (2005: 440). E, de facto, história e portugalidade constituíam, assim, entre si um elo fundamental. Definida a portugalidade como «sinónimo de civilizar, de elevar e dignificar o homem. Elevar os povos atrasados ao nível do ser humano; e dignificá-los de seguida, conferindo-lhes a categoria de cidadãos livres no seio uma Pátria» (SILVA 2010: 86), a história, monumental e imperial, exercia um papel fundamental.

21 Constroí-se, pois, uma essência mitologizada da identidade do colonizador. 0 uso ideológico da educação para a conversão à portugalidade vem, inclusivamente, perverter por completo o suposto rigor científico do ensino, nomeadamente histórico, recheando-o de referências a um nacionalismo celebratório e mitologizado. 0 ensino colonial recorre, então, duplamente ao ahistoricismo, atribuindo, por um lado, uma qualidade ahistórica ao colonizado e constituindo-se, por outro, como uma espécie de história monumental (BHABHA 2004; NIETZSCHE 2004) para se descrever a si próprio. Neste âmbito, é de relembrar a crítica de Friedrick Nietzsche aos usos do que apelida de história monumental. Entendida como «um certo excesso de história», pelo qual «a vida se desmorona e se degenera» e pela qual "grandes segmentos do passado são esquecidos, desprezados e fluem como uma corrente cinzenta ininterrupta», Nietzsche argumenta que a «história monumental ilude por meio de analogias: através de similitudes sedutoras, ela impele os corajosos à temeridade, os entusiasmados ao fanatismo» (2004: 17, 22-23).

Por esta via, o ensino colonial transforma-se em tecnologia de epistemicídio. Superstição e feiticismo são, então, as classificações dadas a práticas e saberes que se encontram do outro lado da linha abissal (cf. SANTOS, MENESES e NUNES 2004; SANTOS 2007; SANTOS e MENESES 2011; MENESES 2011). Segundo Brazão Mazula: «a política educativa do Governo Colonial Português e a sua posição, frente à cultura do colonizado, reflectiam todas essas teorias, para justificar a sua presença na colónia. Então, as "sociedades tradicionais", de "raças inferiores", tinham apenas "usos e costumes" situados no presente, sem memória do passado nem perspectiva de futuro, porque sociedades ágrafas. Negava-se-lhes qualquer dimensão histórica dos seus valores, das suas culturas; e o próprio "indígena" foi considerado "a-histórico" [...]. A dimensão cultural do ensino passava pela desnaturalização do indígena, negando-lhe os seus próprios valores culturais, o seu saber, e cerceando, pela raiz, o 
desenvolvimento natural do seu saber-fazer, considerados "selvagens". Silva Rego, missionário português, antropólogo e consultor do Governo Português Central, ao analisar a "falência" das práticas educativas das massas indígenas por parte das estruturas "mais directamente coloniais", propunha, nos anos 60-70, que a revitalização da aç̧ão civilizadora portuguesa não poderia limitar-se a "imposições de carácter ético e jurídico", mas devia ser de carácter epistemológico. [...] A finalidade era provocar o abandono do conceito tradicional de comunidade, substituindo-o pelo conceito de comunidade portuguesa, no qual o africano devia sentir-se integrado [GALLO 1988: 78], o que correspondia a retirá-lo do seu universo cultural e do mundo da vida - este o significado de "destribalizar" -, para o integrar no espaço português» (1995: s.pag.). ${ }^{8}$

23 O cômputo global da política de instrução e educação colonial é exemplarmente denunciada por Ngugi a Thiong'o:

«The real aim of colonialism was to control the people's wealth [...]. Colonialism imposed its control of the social production of wealth through military conquest and subsequent political dictatorship. But its most important area of domination was the mental universe of the colonized, the control, through culture, of how people perceived themselves and their relationship to the world. Economic and political control can never be complete or effective without mental control. To control a people's culture is to control their tools of self-definition in relationship to others» (1986: 16).

24 No "Guia do alfabetizador "A vitória é certa: a luta continua"», publicado, em 1980, pelo Ministério da Educação da então República Popular de Angola, lê-se:

«Nos últimos anos do colonialismo, ele tentou enganar o Povo, mostrar que se preocupava muito em arranjar mais escolas para os filhos dos camponeses e operários, mas intenção era controlar o Povo, impedir as ideias da libertação de se espalharem, convencer todas as crianças e os seus pais de que eram portugueses e não angolanos, e de que a luta heróica da libertação eram simples actos de terrorismo» (1980: 53).

25 A mesma leitura é veiculada por Américo Boavida. Centrando a sua crítica no «pseudoreformismo colonial português» do início da década de 1960, o autor considerava que

«Em nossos dias, e numa nova etapa, a política colonial portuguesa orienta-se pela via de um pretenso reformismo. Os colonialistas portugueses, com efeito, através de uma propaganda enganosa, esforçam-se em fazer aceitar que os novos projectos e as novas instituições postas em vigor nestes últimos anos - e que não são mais do que a consequência da sublevação armada do povo angolano - têm como objectivo fazer participar a população autóctone na vida administrativa, política, económica e social do país. [...] Todavia, os colonialistas portugueses persistem em recusar o Direito de Angolanidade aos povos e populações angolanas, e impuseram mesmo, por um novo estatuto, a cidadania portuguesa a todos os autóctones» (1981: 48-46).

Os efeitos da razão metonímica são especialmente visíveis nas formas de violência, epistémica, social e ontológica, engendradas pela política colonial de instrução e educação. A sua crítica permite também ver como, no decurso de todas as transfigurações do poder colonial (abolindo formalmente a escravatura e instituindo o trabalho forçado, por exemplo), a experiência dos sujeitos foi marcadamente uma experiência de impossibilidade permanente de auto-nomeação.

27 A crítica à razão metonímica aplicada a esta temática da política de instrução e educação colonial opera, assim, como um campo específico da ampliação do real específico, porque, ao invés, de expandir o real da razão metonímica em função de uma auto-referencialidade que canibaliza a diferença, transfigurando-a como elemento ou 
atestação dos seus pressupostos e da realidade por ela produzida, amplia o real sob o signo do diverso, alertando para a necessidade de visibilizar práticas, conhecimentos, saberes, cosmovisões, sociabilidades que foram sendo historicamente desqualificadas como arcaicas, improdutivas, inferiores, inexistentes e utópicas (no sentido de irrealizáveis) (SANTOS 1999; 2011).

\section{BIBLIOGRAFIA}

BHABHA Homi K., 2004, The location of culture. Londres, Routledge.

BOAVIDA Américo, 1981, Angola. Cinco séculos de exploração portuguesa. Lisboa, Edições 70.

CARVALHO Emílio de, 1995, A igreja Africana no centro da sua história. Subsídios para a história daIgreja nos Países de Língua Oficial Portuguesa. Luanda, Edição do Autor.

HENRIQUES Isabel de Castro, 2003, Território e identidade. O desmantelamento da terra africana e a construção da Angola colonial (c. 1872 - c. 1926). Sumário pormenorizado da lição de síntese apresentada a provas para obtenção do título de Professor Agregado do 4.ํo Grupo (História) da Faculdade de Letras da Universidade de Lisboa. Lisboa, FLUL.

KAJIBANGA Víctor, 1999, «Crise da racionalidade lusotropicalista e do "paradigma” da crioulidade. $O$ caso da antropossociologia de Angola». Comunicação apresentada ao Colóquio $O$ Lusotropicalismo Revisitado, realizado em Lisboa, na Sociedade de Geografia de Lisboa, de 11 a 12 de Fevereiro de 1999.

MAZULA Brazão, 1995, Educação, cultura e ideologia em Moçambique: 1975-1985. Porto, Edições Afrontamento; Fundo Bibliográfico da Língua Portuguesa. [http://www.macua.org/livros/ mazula.html], consultado a 20 de Setembro de 2011.

MENESES Maria Paula G., 2011, «Corpos de violência, linguagens de resistência: as complexas teias de conhecimentos no Moçambique contemporâneo», in Boaventura de Sousa Santos e Maria Paula Meneses, Epistemologias do Sul. Coimbra, Almedina, pp. 201-238.

MUDIMBE V. Y., 1988, The invention of Africa. Gnosis, philosophy and the order of knowledge. Londres, James Currey.

MUDIMBE V. Y.,2013, A invenção de África. Gnose, filosofia e a ordem do conhecimento. Tradução de Ana Medeiros. Luanda, Edições Mulemba; Mangualde, Edições Pedago [«Reler África»].

MWEMBU Donatien Dibwe dia, 2005, «History and memory» in John Edward Philips (org.), Writting African History. Rochester, University of Rochester Press. 439-464.

NETO Maria da Conceição, 1997, «Ideologias, contradições e mistificações da colonização de Angola no século XX», in Lusotopie (Paris), 327-359.

NIETZSCHE Friedrick, 2004, Segunda consideração intempestiva. Da utilidade e desvantagem da história para a vida. Rio de Janeiro, Duamará Distribuidora de Publicações.

NORÉ Alfredo e ADÃo Áurea, 2003, «O ensino colonial destinado aos “indígenas” de Angola. Antecedentes do ensino rudimentar instituído pelo Estado Novo» in Revista Lusófona de Educação, n. ${ }^{\circ}$ 1, pp. 101-122. 
PINTO João Carlos, 1996, «Vantagens da instrução e do trabalho. "Escola de massas” e imagens de uma "educação colonial portuguesa"» in Educação, Sociedade e Cultura, n.ำ 5, pp. 99-128.

SANTOS Boaventura de Sousa, 1999, «Porque é tão difícil construir uma teoria crítica?» in Revista Crítica de Ciências Sociais (Coimbra), n.ํ54, pp. 195-215.

SANTOS Boaventura de Sousa, 2002, A crítica da razão indolente. Contra o desperdício da experiência. Porto, Afrontamento.

SANTOS Boaventura de Sousa, 2006, A gramática do tempo. Para uma nova cultura política. Porto, Afrontamento.

SANTOS Boaventura de Sousa (org.), 2007, Another knowledge is possible. Londres, Verso.

SANTOS Boaventura de Sousa, MENESES Maria Paula e NUNES João Arriscado, 2004, «Introdução: para ampliar o cânone da ciência: a diversidade epistémica do mundo» in Boaventura de Sousa Santos (org.), Semear outras soluções: os caminhos da biodiversidade e dos conhecimentos rivais. Porto, Afrontamento, pp. 19-101.

SANTOS Boaventura de Sousa e MENESES Maria Paula (orgs.), 2011, Epistemologias do sul. Coimbra, Almedina.

SANTOS José Martins dos, 1970, História do ensino em Angola. Luanda, Edição dos Serviços de Educação.

SANTOS José Martins dos,s.d., Cultura, educação e ensino em Angola. Edição digital. Disponível em [http://reocities.com/Athens/troy/4285/ensino.html], consultado em Outubro de 2011.

SILVA José Pinheiro da, 2010, Trincheiras de paz construídas em clima de guerra. Subsídios para a história da educação em Angola (1964-1971). Algés, NEOS.

ZAU Filipe, s.d., Educação em Angola. Novos trilhos para o desenvolvimento. [http:// www.adelinotorres.com/teses/Filipe\%20ZAU_Educa\%E7ao\%20em\%20Angola.pdf], consultado a 12 de Dezembro de 2011.

\section{NOTAS}

1. O autor refere-se aqui ao que se poderia denominar de abordagem neolusotropicalista que Kajibanga (1999) e Zau (s.d.) também criticam. Esta passa, essencialmente, pela reafirmação das especificidades e singularidades positivas do colonialismo português. No que diz respeito à educação, tais especificidades salientariam o contributo da escola colonial para o processo civilizacional angolano.

2. Na verdade, as posições oscilavam entre a que defendia a acção educativa dirigida às populações africanas como forma de as elevar civilizacionalmente (como foi o caso dos pedagogos Adolfo Coelho [1847-1919] e Simões Raposo [1840-1900]) e os partidários da ideia, segundo a qual tal seria absurdo (dos quais se salienta António Ennes [1848-1901], que chegou a ocupar o cargo de Ministro da Marinha e do Ultramar entre 1890 e 1891, e o político e historiador Oliveira Martins [1845-1894]).

3. Em Angola, vingou apenas a Escola Principal de Luanda que vigorou até cerca de 1906.

4. Nas palavras de Norton de Matos: «Muitas vezes tenho dito que não sou apologista da educação intensa literária, porque opto pelo princípio de que em vez de literatos se formem homens de acção e de trabalho» (1946, cit. in NORÉ e ADÃO 2003: 110).

5. O acordo entre o Estado Novo e a Igreja ficou conhecido como «Aliança de Cruz e Espada». Segundo Emílio Carvalho, «o governo político fascista de Oliveira Salazar celebra com a Santa Sé a 
Concordata e o Acordo Missionário, no Vaticano, a 7 de Maio de 1940, dando assim satisfação aos protestos veementes e colectivos do episcopado português e do Papa Pio X, na sua encíclica "Jandundum in Lusitania", contra as medidas restritivas contidas na Lei da Separação do Estado e das Igrejas de 1911. Esses dois documentos passaram a regular as relações entre o Estado e a Igreja portugueses. Tal "conspiração" [...] facilitou o esforço missionário das Missões católicas, reconsagrando-as nas colónias como "instrumentos de civilização e de influência nacional", as únicas reconhecidas como instrumentos de nacionalização e assimilação [...]. Foi o Decreto-Lei n.․ 30665, de 22 de Agosto de 1940, que criou nos estabelecimentos de ensino técnico, médio e elementar, a disciplina de educação moral e cívica, na qual se abrangeu o ensino da religião e da moral católica, durante uma hora por semana» (1995: 27-29).

6. Embora em 1961 - ano de importantes alterações legislativas -, tivesse sido já posta em marcha uma reforma do ensino, esta foi só oficializada com o Decreto n.․ 45.908 de 1964 .

7. O Governador-Geral Silvino Silvério Marques apostou, neste âmbito, numa política de ocupação escolar das fronteiras de Angola (MARTINS s.d.).

8. A mesma crítica era veiculada pelo MPLA - Movimento Popular de Libertação de Angola: «A análise dos planos de estudo, dos programas e dos manuais de ensino mostra que estes pouco ou nada transmitiam sobre a realidade angolana ou africana, mas sim, quase que exclusivamente, sobre Portugal e a Europa. Nas missões católicas e protestantes só o catecismo era ensinado nas línguas africanas de Angola. A escola apresentava uma dimensão totalmente estrangeira para a grande maioria dos angolanos e como instrumento de identidade serviu, essencialmente, os interesses coloniais» (MPLA 1978: 41).

\section{RESUMOS}

Enquanto sector da política colonial portuguesa, a instrução e a educação colonial serão abordadas como elemento estruturante da dominação colonial e como campo de exercício da razão metonímica (cf. SANTOS 2002; 2006).

Procurar-se-á, pois, problematizar a temática da instrução e educação colonial em Angola, focando especialmente a década de 1960. Nesse contexto particular, a educação era encarada, simultaneamente, como instrumento de luta contra a «insurreição terrorista» que se espalhava por Angola e como um instrumento de promoção da adesão das comunidades à portugalidade, tornando-as imunes à «rebelião». Será, pois, um ideal instrumental de portugalidade e os propósitos de afrontamento e neutralização das ideologias nacionalistas, que irão orientar a acção educativa colonial. Esse ideal de portugalidade servirá ao fortalecimento dos propósitos «integracionistas» e «assimilacionistas», na medida em que «todos quantos pensam, sentem e agem à luz dos valores morais, espirituais e religiosos da Casa Lusitana são portugueses. Em rigor, a integração é, entre nós, uma mentalidade. Define um estilo de vida» (SILVA 2010: 16).

As a sector of the colonial Portuguese policy, instruction and colonial education will be addressed as a structural element of colonial domination and as a field for the exercise of metonymic reason (cf. SANTOS 2002; 2006). This article aims to discuss the theme of instruction and colonial education in Angola, especially focusing on the 1960s context, in which the education was simultaneously viewed as a tool to combat «terrorist insurgency» that was spreading through Angola and as a tool to promote the commitment of the communities to Portuguese nationality, making them immune to the «rebellion». It will be an instrumental ideal of Portugalidade and it will be purposes of neutralization of nationalist ideologies, which will guide the colonial educational activity. This ideal of Portugalidade serve to strengthen «integrationist» and 
«assimilationist» purposes. In fact, "all who think feel and act in the light of moral, spiritual amd religious values of Casa Lusitana are Portuguese. Strictly speaking, integration is among us a mindset. Defines a lifestyle»(SILVA 2010: 16).

ÍNDICE

Keywords: education, colonialism, Angola

Palavras-chave: educação, colonialismo, Angola

\section{AUTOR}

\section{CATARINA ANTUNES GOMES}

catarinaantunesgomes@gmail.com

Professora Auxiliar do Departamento de Sociologia da Faculdade de Ciências Sociais (FCS) da Universidade Agostinho Neto (UAN).

Doutorada e Mestre em Sociologia pela Faculdade de Economia da Universidade de Coimbra; licenciada em Antropologia Social e Cultural pela Faculdade de Ciências e Tecnologia da mesma instituição. É Professora Auxiliar do Departamento de Sociologia da Faculdade de Ciências Sociais (FCS) da Universidade Agostinho Neto (UAN) e investigadora do Centro de Estudos Sociais (CES) da Universidade de Coimbra. É autora de vários artigos e livros, dos quais se salientam: Os espelhos quebrados de Narciso: diálogos pós-coloniais sobre história e memória em Angola (Asylon, 2014); «When Sophia hears Miguel or trying to transcend abyssal lines: why does it matter to Europe?», Révue de Philosophie (Post-) Europèenne, 2013; «Evolutionism is dead! Long live evolutionism. News paths of coloniality of reason and knowledge» (Terra, 2012); As equações não lineares da democracia (Coimbra, Almedina, 2012). 